\title{
Effectiveness of a Training Program for Improving Public Health Nurses' Attitudes and Confidence in Dealing with Men Who Have Sex with Men
}

\author{
Asuka Waki' ${ }^{1}$ Yumiko H. Nishimura², Mieko Iwai ${ }^{3}$, Gaku Okamoto4, Mikiko Ito5, \\ Yasuharu Hidaka ${ }^{6}$ \\ ${ }^{1}$ Faculty of Nursing, Senri Kinran University, Osaka, Japan \\ ${ }^{2}$ School of Nursing, Kansai University of Nursing and Health Sciences, Hyogo, Japan \\ ${ }^{3}$ Double-Eyes, Hyogo, Japan \\ ${ }^{4}$ Division of Medical Counseling, National Hospital Organization Osaka National Hospital, Osaka, Japan \\ ${ }^{5}$ Department of Public Health Nursing, Shiga University of Medical Science, Otsu, Japan \\ ${ }^{6}$ School of Nursing, Takarazuka University, Osaka, Japan \\ Email: asukawaki38@gmail.com
}

How to cite this paper: Waki, A., Nishimura, Y.H., Iwai, M., Okamoto, G., Ito, M. and Hidaka, Y. (2017) Effectiveness of a Training Program for Improving Public Health Nurses' Attitudes and Confidence in Dealing with Men Who Have Sex with Men. Open Journal of Nursing, 7, 169-184. https://doi.org/10.4236/ojn.2017.72015

Received: November 9, 2016

Accepted: February 6, 2017

Published: February 9, 2017

Copyright $\odot 2017$ by authors and Scientific Research Publishing Inc. This work is licensed under the Creative Commons Attribution International License (CC BY 4.0).

http://creativecommons.org/licenses/by/4.0/

CC) $\underset{\mathrm{EY}}{0}$ Open Access

\begin{abstract}
Objective: This study examined the effect of an educational intervention on public health nurses' attitudes and confidence in dealing with men who have sex with men (MSM). In Japan, HIV is primarily transmitted through sexual contact between men, and free HIV testing and counseling are provided by public health nurses. However, because of a lack of education, public health nurses do not often recognize the existence of MSM in daily life. Thus, improving public health nurses' understanding of MSM is crucial. Methods: This study used a quasi-experimental design to examine public health nurses' homophobia, confidence in dealing with MSM, and low awareness of MSM in daily life at pre-test, post-test, and 1 and 3 months follow-ups. The intervention comprised a 3-hour training session conducted between November 2012 and September 2013 in the Kinki region. Results: A total of 124 public health nurses participated in the training, 117 of which were allocated to the intervention group; 182 public health nurses who did not participate in the training session were allocated to a control group. Homophobia scores had significantly decreased at post-test, and remained at that low level by the follow-up at 3 months (pre-test to post-test; $\mathrm{p}=0.00$, post-test to 1 month; $\mathrm{p}=0.83,1$ month to 3 months; $\mathrm{p}=0.64$, pre-test to 3 months; $\mathrm{p}=0.00$ ). Confidence in dealing with MSM and recognition of MSM had significantly increased by post-test; these were also maintained by the follow-up at 3 months (pre-test to
\end{abstract}


post-test; $\mathrm{p}=0.0$, post-test to 1 month; $\mathrm{p}=0.18,1$ to 3 months; $\mathrm{p}=0.44$, pre-test to 3 months; $\mathrm{p}=0.0$ ). Discussion: While the three-hour training session was short, it was effective for improving attitudes toward MSM and building confidence in dealing with them.

\section{Keywords}

Men Who Have Sex with Men, Public Health Nurse, HIV, Test, Training

\section{Introduction}

In Japan, the major route of HIV transmission is sexual contact, particularly male-to-male homosexual contact: In 2015, among the 1006 newly infected HIV cases, 691 (68.7\%) were the result of male homosexual contact. Altogether, maleto-male homosexual contact was the transmission route for 10,379 HIV cases (58.0\%) and for 3215 AIDS cases (39.8\%) [1].

The Ministry of Health, Labour and Welfare revised the national AIDS prevention guidelines in 2012. The guidelines indicate that specific measures should be taken to ensure that men who have sex with men (MSM) receive appropriate health care services, as these services are currently lacking for them. To fill the gap in services, the guidelines recommended improving the quality of HIV counseling and testing services for MSM and better encouraging behavioral change [2]. Earlier, Japan began offering free and anonymous HIV tests and counseling at public health centers in all prefectures. Such counseling and testing services are well known to MSM, with around 50\% of MSM having utilized this service at health centers [3].

In public health centers, public health nurses tend to be responsible for conducting pre-test counseling and negative result notification. When the results are positive, the doctor is responsible for the positive result consultations, while public health nurses provide psychosocial care and information. The quality of public health nurses' pre-test counseling and result notification has been found to influence the preventive and care seeking behavior of patients after positive result notification [4]. However, problematically, public health nursing education does not place much emphasis on HIV education. HIV is typically regarded as part of infection control education, which prioritizes epidemic diseases such as Zika fever, measles, and tuberculosis because of their potential to rapidly spread across entire communities. The establishment of clear treatment plans and the rather small at-risk population have made HIV education a low priority. Furthermore, such education typically focuses on the virology and pathophysiology of the disease. Public health nurses must undergo both the basic nursing education and specialized education for public health nurses. In the former curricula, sexuality is often taught in the context of maternal nursing [5] and reproduction, and thus focuses on heterosexual patients. For that reason, after graduation, public health nurses are under-informed of the diversity of sexuality 
and health problems of MSM and thus are ill equipped for their treatment. Public health nurses also do not readily recognize homosexual patients. One survey of MSM on the conditions of HIV testing and counseling showed that public health nurses often provide counseling under the preconception of the client being a heterosexual man [6].

Based on this background, this study examined whether a training session could improve recognition and deepen understanding of MSM in daily settings among Japanese public health nurses. It is assumed that this would improve care for MSM.

\section{Background}

\subsection{HIV Care and Homophobia among Health Care Providers}

According to the United Nations Population Fund, in 2014, MSM accounted for $8 \%$ of all new HIV infections globally. It further recommends that health care provider create a safe and supportive relationship with MSM, given their high risk of experiencing stigma or discrimination in accessing health care services; indeed, homophobic attitudes by health care providers dissuade MSM from HIV testing and prevention behavior [7].

Homophobia among health care providers and its related factors have been explored empirically since the 1990s. The identified factors related to attitudes toward homosexuality differ according to religion and culture. Religion has been demonstrated to influence homophobic attitudes in England, Malaysia, and Taiwan [8] [9] [10], while high education levels relate to less homophobic attitudes among nurses and nursing students [10] [11]. Nurses with homosexual friends or relatives and who had experience in treating homosexual people were more likely to have positive attitudes toward homosexuality. In contrast, nurses who had had more work experience and labeled themselves as heterosexual were more likely to adopt negative attitudes [10].

It has been argued that education is best suited to reducing the homophobic attitudes of health care workers and students. This could involve curriculum changes that promote cultural diversity and sensitivity and increasing clinical exposure to MSM [9]. However, there are only two interventional studies for college students [12] [13], and only one for reducing homophobic attitudes among nurses in the United States [14]. In Japan, there are not yet any interventional studies on this topic.

\subsection{HIV Care and Public Health Nurses' Attitudes toward MSM in Japan}

In Japan, public health nurses play vital roles as entry points of HIV care for MSM. There has been no research on homophobic attitudes among Japanese public health nurses. While there are some in other Asian countries, they cannot simply be applied to Japan because of differences in culture and epidemiological conditions. While there are numerous training programs on HIV testing for providers in Japan, no studies have measured their outcomes. 
Researchers conducted a survey to grasp the actual situation of HIV testing and perceptions of counseling among 1535 public health nurses in the Kinki region in 2011 [15]. The majority (52.8\%) reported perceiving numerous or some difficulties regarding HIV/AIDS services, despite having work experience in HIV/AIDS. Regarding their encounters with MSM during practice, 49.3\%, $13.5 \%$, and $36.8 \%$ reported "yes", "no", and “don't know", respectively. In other words, public health nurses have difficulty recognizing MSM in daily practice.

Recently, MSM have become more visible because of homosexual personalities' and celebrities' disclosing their sexual orientation and media reports about homosexuality. However, Inaba [16] noted that heterosexual people have inaccurately portrayed homosexuality and the reality of living with it in media reports, which might make it difficult for public health nurses to understand the daily lives of MSM.

\subsection{Research Questions}

This study was conducted to answer the following specific research questions:

1) Does participation in the training program change Japanese public health nurses' homophobic attitudes, confidence in dealing with MSM, and recognition of MSM in daily practice?

2) How do the training-related effects in these variables change over time?

\section{Methods}

\subsection{Design}

This study was a quasi-experimental design, measuring the above variables in two groups (intervention and control) at four time points: pre-test, post-test, and follow-ups at 1 and 3 months.

\subsection{Setting and Participants}

The Kinki region, which is located in mid-west Honshu, is the second largest urban and economic area. It comprises six prefectures. Since 1998, the number of reported HIV cases has increased in the Kinki region; annually since 2004, the number of reported cases in this region has been the second largest after Tokyo. Furthermore, in 2015, among the 47 prefectures in Japan, Osaka prefecture, which is in the central Kinki region, had the second largest number of reported cases of HIV (168 cases), while Hyogo prefecture had the tenth (21 cases); Tokyo had the largest (364 cases) [1]. Figure 1 shows the flow chart describing the numbers of participants who responded and did not respond. As of this study, the Kinki region had 174 health centers. The participants were recruited by cooperating with the prefectural divisions of infectious disease control and prevention in the Kinki region. Each prefectural division asked each health centers to participate in the study. Health centers that agreed to participate selected at least one full-time public health nurse for the training session as well as other nurses who would not participate; the former were allocated to the intervention group, and the latter to the control group. The ratio of intervention to control partici- 


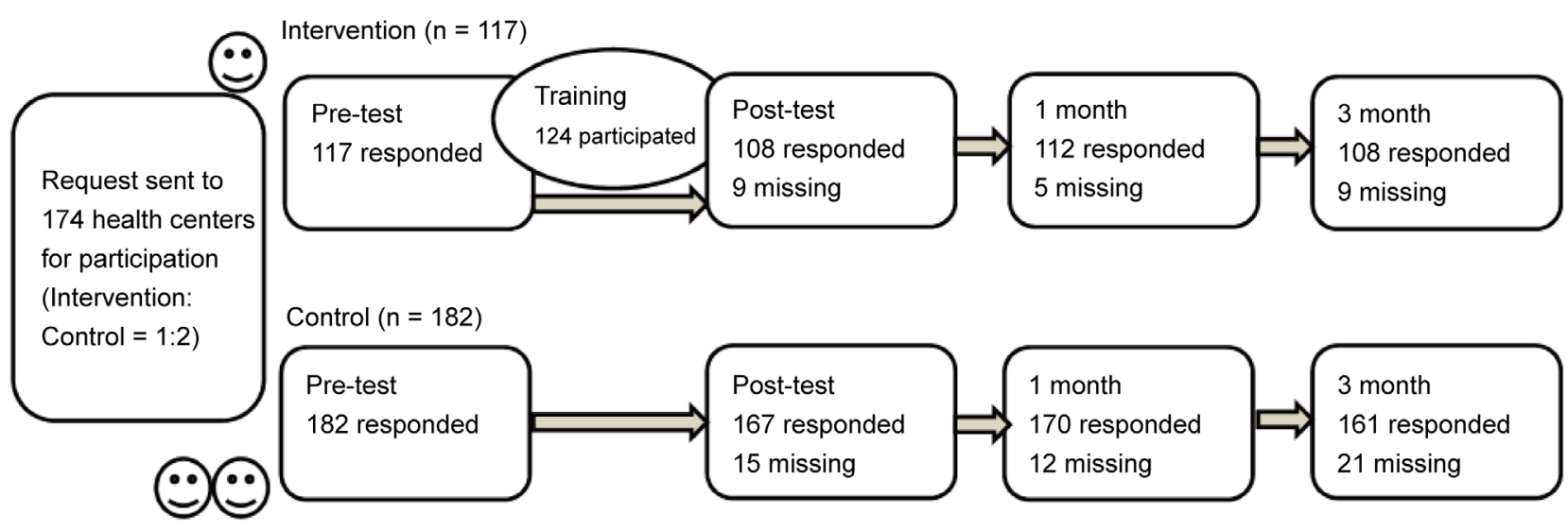

Figure 1. The flow chart describing the number of participants who responded and did not respond.

pants was 1:2 in each health center. This study aimed to provide an exhaustive survey of the whole Kinki region. In 2009, the number of public health nurses was 2235 , and this study sought to recruit more than $10 \%$ (more than 225) of this number in total. From the perspective of feasibility and training quality, the estimated maximum number of participants who could participate in the training was around 130. In contrast, for control group participants, it was assumed that there would be a $50 \%$ of dropouts until 3 months follow-up.; thus, the ratio of intervention to control participants at each health center was set to 1:2. Participation in the training was voluntary. The analyzed sample included all participants who responded to the pre-test questionnaire. The participants who did not respond to the pre-test questionnaire were excluded because their characteristics would not be accessible. Similarly, the participants who did not respond to the questionnaire at each time (because they were busy, forgot, or had transferred) were excluded.

\subsection{Intervention}

Table 1 shows the training objectives, content, and teaching strategies. Instructors and facilitators comprised a midwife specializing in nursing education, a sociologist, a pedagogist, a psychologist specializing in health issues of MSM, and a medical social worker. The training was designed to improve recognition and deepen understanding of MSM in daily practice. The training format was a 3-hour workshop comprising lectures combined with discussion in small groups of 5 or 6 participants. Before training, a simulated training session was held with imitation participants to confirm that the time allocation, contents, and participant responses were appropriate.

The training contents were based on the findings of 2011 study. In that survey, many public health nurses reported wanting lectures from MSM on their daily lives. Unfortunately, this was not included in the actual training session in the study. Instead, the researchers aimed to improve recognition of MSM in daily settings by presenting statistics on the proportion of lesbian, gay, bisexual, and transgender (LGBT) in the total population of Japan (7.6\%) [17]. The psycho- 
Table 1. Training objectives, content, and teaching strategies.

\begin{tabular}{|c|c|c|c|c|}
\hline Theme & $\begin{array}{l}\text { Time } \\
\text { allocation }\end{array}$ & Objective & Contents & Teaching strategy \\
\hline & & $\begin{array}{l}\text { Introduction to training and } \\
\text { sharing training objectives }\end{array}$ & $\begin{array}{l}\text { Explanation of training background and sharing training } \\
\text { objectives }\end{array}$ & $\begin{array}{l}\text { Lecture with slides, } \\
\text { presented by an author }\end{array}$ \\
\hline Introduction & $45 \mathrm{~min}$ & $\begin{array}{l}\text { Create a safe environment to talk } \\
\text { about sensitive topics such as } \\
\text { sexuality and individual } \\
\text { perceptions of sex } \\
\text { Create a positive learning } \\
\text { environment }\end{array}$ & $\begin{array}{l}\text { Sharing the ground rules of the training: (1) Protection of } \\
\text { participants' personal information, (2) respect others, } \\
\text { (3) do not criticize others. }\end{array}$ & $\begin{array}{l}\text { Lecture with posters, } \\
\text { presented by a pedagogist, } \\
\text { and an ice-breaker activity }\end{array}$ \\
\hline
\end{tabular}

\begin{tabular}{|c|c|c|c|c|}
\hline \multirow{5}{*}{ MSM } & \multirow{5}{*}{$110 \mathrm{~min}$} & $\begin{array}{l}\text { 1. Obtain knowledge their own } \\
\text { attitudes toward MSM }\end{array}$ & $\begin{array}{l}\text { (1) Verbalizing attitudes (both positive and negative) } \\
\text { toward MSM; (2) Classifying personal attitudes toward } \\
\text { MSM and attitudes as a public health nurse }\end{array}$ & $\begin{array}{l}\text { Individual work facilitated } \\
\text { by a pedagogist }\end{array}$ \\
\hline & & $\begin{array}{l}\text { 2. Share images with other } \\
\text { participants, relativize attitudes, } \\
\text { and encourage recognition of } \\
\text { their own perceptions of MSM }\end{array}$ & $\begin{array}{l}\text { Sharing ideas on attitudes toward MSM via small group } \\
\text { discussion, understanding the differences in such attitudes, } \\
\text { and relativization of own perceptions with those of others. }\end{array}$ & $\begin{array}{l}\text { Group discussion } \\
\text { facilitated by a pedagogist }\end{array}$ \\
\hline & & $\begin{array}{l}\text { 3. Describing the daily lives of } \\
\text { MSM } \\
\text { 4. Imagine the difficulties } \\
\text { relating to health and daily life } \\
\text { of MSM } \\
\text { 5. Describe public health nurses' } \\
\text { supportive role for MSM }\end{array}$ & $\begin{array}{l}\text { (1) Definitions of sexuality and sexual minorities, } \\
\text { proportion of MSM in the general population ( } 7.6 \% \text { of the } \\
\text { general population of Japan); (2) Health issues among } \\
\text { homosexual people (e.g., mental health, alcohol and drug } \\
\text { abuse, risky sexual behavior, suicide attempts); (3) life } \\
\text { difficulties of MSM (e.g., friendless in school, existence of } \\
\text { heterosexual role trouble, strong need for psychological } \\
\text { counseling); (4) required attitudes of health care providers } \\
\text { for dealing with MSM; and (5) required support for MSM. } \\
\text { To improve understanding of MSM's daily lives, we } \\
\text { introduced movies, comics, and YouTube videos about } \\
\text { MSM. }\end{array}$ & $\begin{array}{l}\text { Lecture with slides, } \\
\text { presented by a } \\
\text { psychologist, and a } \\
\text { question and answer } \\
\text { session }\end{array}$ \\
\hline & & $\begin{array}{l}\text { 6. Understand the existence of } \\
\text { informational resources for } \\
\text { supporting and understanding } \\
\text { MSM }\end{array}$ & $\begin{array}{l}\text { Local resources list of necessary information for dealing } \\
\text { with MSM, such as the contact address and website of } \\
\text { nonprofit organization supporting MSM (e.g. PLWHA) in } \\
\text { each prefecture, as well as downloadable research reports } \\
\text { on MSM and brochures for MSM from the PLWHA, and a } \\
\text { list of the novels, movies, YouTube videos that offer } \\
\text { information on the daily lives of MSM. }\end{array}$ & $\begin{array}{l}\text { Distribution of resource } \\
\text { list as well as documents } \\
\text { and books in the lecture } \\
\text { hall so that participants } \\
\text { can read during the break. }\end{array}$ \\
\hline & & $\begin{array}{l}\text { 7. Share own attitudes about } \\
\text { MSM based on knowledge } \\
\text { acquired from the training. }\end{array}$ & $\begin{array}{l}\text { Based on their experiences of sharing the perceptions of } \\
\text { MSM in small-group discussions, the knowledge gleaned } \\
\text { from lectures on MSM, recapitulation of their own } \\
\text { perceptions of towards MSM (especially negative attitudes) } \\
\text { through the training, has anything changed? }\end{array}$ & $\begin{array}{l}\text { Individual work facilitated } \\
\text { by a pedagogist }\end{array}$ \\
\hline
\end{tabular}

MSM, men who have sex with men; PLWHA, People Living with HIV/AIDS.

logical background and health issues of MSM were also covered, and participants were introduced to cinema, comics, and YouTube videos about MSM.

Morrissey and Rivers mentioned that to provide high quality care to LGBT clients, nurses and other health professionals must closely examine their own feelings and attitudes concerning homosexuality [17]. Thus, participants were asked to reflect on their attitudes towards MSM and encouraged group discussions to share their feelings and attitudes. The training comprises a combination of group discussions, lectures, and individual work to prompt participant inte- 
ractions and relativization of their attitudes. The researchers also distributed a local resource list of necessary information to deal with MSM, such as the contact address and website of a nonprofit organization supporting MSM, People Living with HIV/AIDS (PLWHA), in each prefecture.

\subsection{Data Collection}

The training program was held was held 8 times in total, at least once in each of the six prefectures of the Kinki region, between November 2012 and September 2013. Since there were numerous public health nurses in Osaka and Hyogo prefectures, the training was conducted twice in these prefectures to improve its coverage. Before the training, the pre-and post-test questionnaires were sent to the participating health centers, which then distributed these questionnaires to the public health nurses of both groups. The questionnaires were all anonymous, and participants completed them by themselves. The questionnaires were collected in each center and returned to the authors after the training. The followup questionnaires were sent at 1 and 3 months after the training program ended, and data collection was conducted in the same manner at follow-up as at the first two administrations. To identify the respondents and match questionnaires at each time point, ID number seals were distributed at pre-test and participants were asked to apply the seal to each questionnaire completed. If participants lost their ID seal, their mothers' names could be written to enable matching.

\subsection{Measures}

\subsubsection{Sociodemographic Variables}

Sociodemographic background variables included age, sex, education level, years of experience as a public health nurse, experience of previous contact/interaction with MSM, and previous sexuality training.

\subsubsection{Attitudes toward Homosexuality}

The Japanese version of the Index of Homophobia (JIHP) was used to assess public health nurses' attitudes toward homosexual people [18]. The original scale was developed by Hudson and Ricketts [19]. Kaji determined the JIHP's reliability using the Cronbach's alpha coefficient (0.9147). This scale was chosen for its high reliability and focus on attitudes toward homosexuality rather than on participants' cognitive and emotional responses to them. The scale comprises 25 items (e.g., "You would be uneasy in a group of homosexual individuals" and "I would feel disappointed if I learned that my child was homosexual"). These were answered on a 5-point scale with response options of 0 (strongly agree), 1 (agree), 2 (neither agree nor disagree), 3 (disagree), and 4 (strongly disagree), with higher scores indicating more homophobic attitudes. Scores of 0 - 25 indicate non-homophobic, 26 - 50 indicate moderately non-homophobic, 51 - 75 indicate moderately homophobic, and 76 - 100 indicate homophobic. The reliability (Cronbach's alpha) of the JIPH in this sample was 0.92at pre-test. Missing JIPH scores were replaced using mean substitution if at least half of the items were completed. 
To measure confidence in dealing with MSM, a one-item measure was developed for this study. The item was "Do you have confidence in dealing with MSM or people who you believe to be MSM?" This was answered on a 4-point scale, with response options of 4 (very confident), 3 (confident), 2 (not so confident), and 1 (not at all confident). Higher scores indicated high confidence in dealing with MSM.

To measure recognition of MSM in daily practice, another one-item measure was developed. This item was "Do you think that there are MSM among your family, relatives, friends, and colleagues, or anybody else you are familiar with?" The 4-point scale used to rate this item included response options of 4 (must be), 3 (might be), 2 (might not be), and 1 (might not be). Responses of "must be" and "might be" were grouped as "yes" and those of "might not be" and "must not be" were grouped as "no".

\subsection{Ethical Consideration}

The study protocol was approved by the institutional review board of the researchers' university and six prefectures in the Kinki region. Both instructors and participants agreed to protect the personal information of participants and respect others at the beginning of training session. All public health nurses in the in Kinki region who did not participate in the training were given a pamphlet of the training contents. All participants responded to the questionnaire voluntarily, and their consent was implied by the return of the questionnaires. The first and fifth authors take complete responsibility for the integrity of the data and the accuracy of the data analysis.

\subsection{Statistical Analysis}

All statistical analyses were conducted using IBM SPSS Statistics 23.0. Data were analyzed using both descriptive and comparative statistics. Baseline differences in categorical and continuous variables between intervention and control groups were tested using the chi-square test and Student's t-test, respectively. The Mann-Whitney $U$ test was used to compare the scores for the recognition of MSM measure between the intervention and control group. Differences in scores on the JIPH and confidence in dealing with MSM measure between each time point (pre-test, post-test, 1 and 3 month follow-ups) were examined for significant differences using paired t-tests, and Wilcoxon's signed-rank test was used to examine changes in scores for the recognition of MSM measure. The threshold for significance was $\mathrm{p}<0.05$.

\section{Results}

One hundred twenty-four public health nurses ultimately participated in the training, of which 117 were analyzed (and thus formed the intervention group). The control group comprised 182 public health nurses who responded to the pre-test questionnaire. 


\subsection{Participant Characteristics}

Table 2 shows the sociodemographic characteristics of the participants. Intervention group participants were significantly younger than were control group participants $(\mathrm{t}(292)=-2.487, \mathrm{p}=0.02)$, and the intervention group had significantly less experience as public health nurses $(\mathrm{t}(291)=-2.273, \mathrm{p}=0.11)$. There were significant differences between the groups regarding the experience of dealing with MSM $\left(\chi^{2}=4.325, \mathrm{df}=1, \mathrm{p}=0.04\right)$. None of the other sociodemographics significantly differed between the groups.

\subsection{Main Outcome Measures at Pretest}

Table 3 shows the main outcome measures at pre-test. There were no significant

Table 2. Sociodemographic characteristics of study subjects at pre-test.

\begin{tabular}{|c|c|c|c|c|c|c|c|}
\hline \multirow{2}{*}{ Sociodemographic background } & \multicolumn{2}{|c|}{ All participants $(\mathrm{N}=299)(\%)$} & \multicolumn{2}{|c|}{ Intervention $(\mathrm{N}=117)(\%)$} & \multicolumn{2}{|c|}{ Control $(\mathrm{n}=182)(\%)$} & \multirow[t]{2}{*}{$\mathrm{p}$} \\
\hline & & & & & & & \\
\hline \multicolumn{8}{|l|}{ Age } \\
\hline Range & $23-61$ & & $23-60$ & & $24-61$ & & \\
\hline Mean (SD) & 38.9 & $(10.6)$ & 37.2 & $(10.1)$ & 40.1 & $(10.9)$ & $0.02^{\mathrm{a}}$ \\
\hline Median & 38 & & 35 & & 40 & & \\
\hline \multicolumn{8}{|l|}{ Sex } \\
\hline Female & 287 & $(97.4)$ & 114 & $(97.4)$ & 173 & $(95.1)$ & $0.3^{\mathrm{b}}$ \\
\hline \multicolumn{8}{|l|}{ Educational status } \\
\hline Diploma & 124 & $(41.5)$ & 48 & $(41.0)$ & 76 & $(41.8)$ & $0.65^{\mathrm{b}}$ \\
\hline Associate degree & 32 & $(10.7)$ & 14 & $(12.0)$ & 18 & (9.9) & $0.84^{\mathrm{b}}$ \\
\hline Bachelor's degree & 110 & $(36.8)$ & 48 & $(41.0)$ & 62 & $(34.1)$ & $0.35^{\mathrm{b}}$ \\
\hline Master's degree & 16 & $(5.4)$ & 5 & $(4.3)$ & 11 & $(6.0)$ & $0.45^{\mathrm{b}}$ \\
\hline \multicolumn{8}{|l|}{$\begin{array}{l}\text { Years of experience as a public } \\
\text { health nurse }\end{array}$} \\
\hline Range & $0-39$ & & $0-38$ & & $0-39$ & & \\
\hline Mean (SD) & 14 & $(11.0)$ & 12 & $(10.2)$ & 15.3 & (11.4) & $0.01^{\mathrm{a}}$ \\
\hline Median & 11.5 & & 8 & & 15 & & \\
\hline $\begin{array}{l}\text { Have contact/interacted with } \\
\text { MSM }\end{array}$ & 135 & $(45.2)$ & 62 & (53.9) & 73 & $(41.5)$ & $0.04^{\mathrm{b}}$ \\
\hline Have received sexuality training & 167 & $(55.9)$ & 68 & (59.6) & 99 & $(57.6)$ & $0.72^{\mathrm{b}}$ \\
\hline
\end{tabular}

a Two-group $\mathrm{T}$ test and $\mathrm{b}$ Chi-Square test.

Table 3. Main outcome measures at pre-test.

\begin{tabular}{cccccc}
\hline & \multicolumn{2}{c}{ Intervention $(\mathrm{n}=117)(\%)$} & \multicolumn{2}{c}{ Control (n=182) (\%) } & $\mathrm{p}$ \\
\hline JIPH: Attitudes toward homosexuality (SD) & 39.1 & $(12.2)$ & 41.5 & $(14.7)$ & $0.15^{\mathrm{a}}$ \\
Confidence in dealing with MSM (SD) & 1.84 & $(0.61)$ & 1.88 & $(0.67)$ & $0.6^{\mathrm{a}}$ \\
Recognition of MSM in daily practice (SD) & 0.59 & $(0.49)$ & 0.51 & $(0.50)$ & $0.17^{\mathrm{b}}$ \\
\hline
\end{tabular}

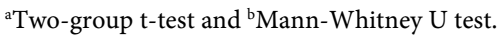


differences between the groups in JIPH scores $(\mathrm{t}(294)=-1.457, \mathrm{p}=0.15)$, confidence in dealing with MSM $(\mathrm{t}(294)=-0.523, \mathrm{p}=0.60)$, or recognition of MSM in daily life $(\mathrm{U}=9542, \mathrm{p}=0.17)$. Thus, there were no significant differences regarding the primary measures at pretest between the two groups.

\subsection{Chronological Changes in Outcomes}

Table 4 shows the means and standard deviations of all main outcome measures at pre-test, post-test, and the follow-ups (1 and 3 months). Regarding the JIPH scores, there was a significant decrease between pre-test and post-test and between pre-test and the follow-up at 3 months in both groups (intervention group: pre- to post-test, $\mathrm{t}(106)=6.32, \mathrm{p}=0.00$, pre-test to 3 months, $\mathrm{t}(106)=$ $5.86, \mathrm{p}=0.00$; control group: pre- to post-test, $\mathrm{t}(162)=2.91, \mathrm{p}=0.0$, pre-test to 3 months, $\mathrm{t}(162)=4.04, \mathrm{p}=0.00)$. However, there were no significant differences between post-test and 1 month, or between 1 and 3 months in either group (intervention group: post-test to 1 month, $\mathrm{t}(106)=0.22, \mathrm{p}=0.83,1$ to 3 months, $\mathrm{t}(106)=0.473, \mathrm{p}=0.64$; control group, post-test to 1 month, $\mathrm{t}(162)=1.42, \mathrm{p}=$ $0.16,1$ to 3 months, $\mathrm{t}(162)=1.13, \mathrm{p}=0.26)$.

Regarding the confidence in dealing with MSM, in the intervention group, there were significant differences in the mean scores between pre-test and posttest $(t(105)=5.77, p=0.00)$, and between pre-test and the follow-up at 3 months

Table 4. Means and standard deviations for all variables at pre-test, post-test, and follow-up (1 and 3 months) in intervention and control groups.

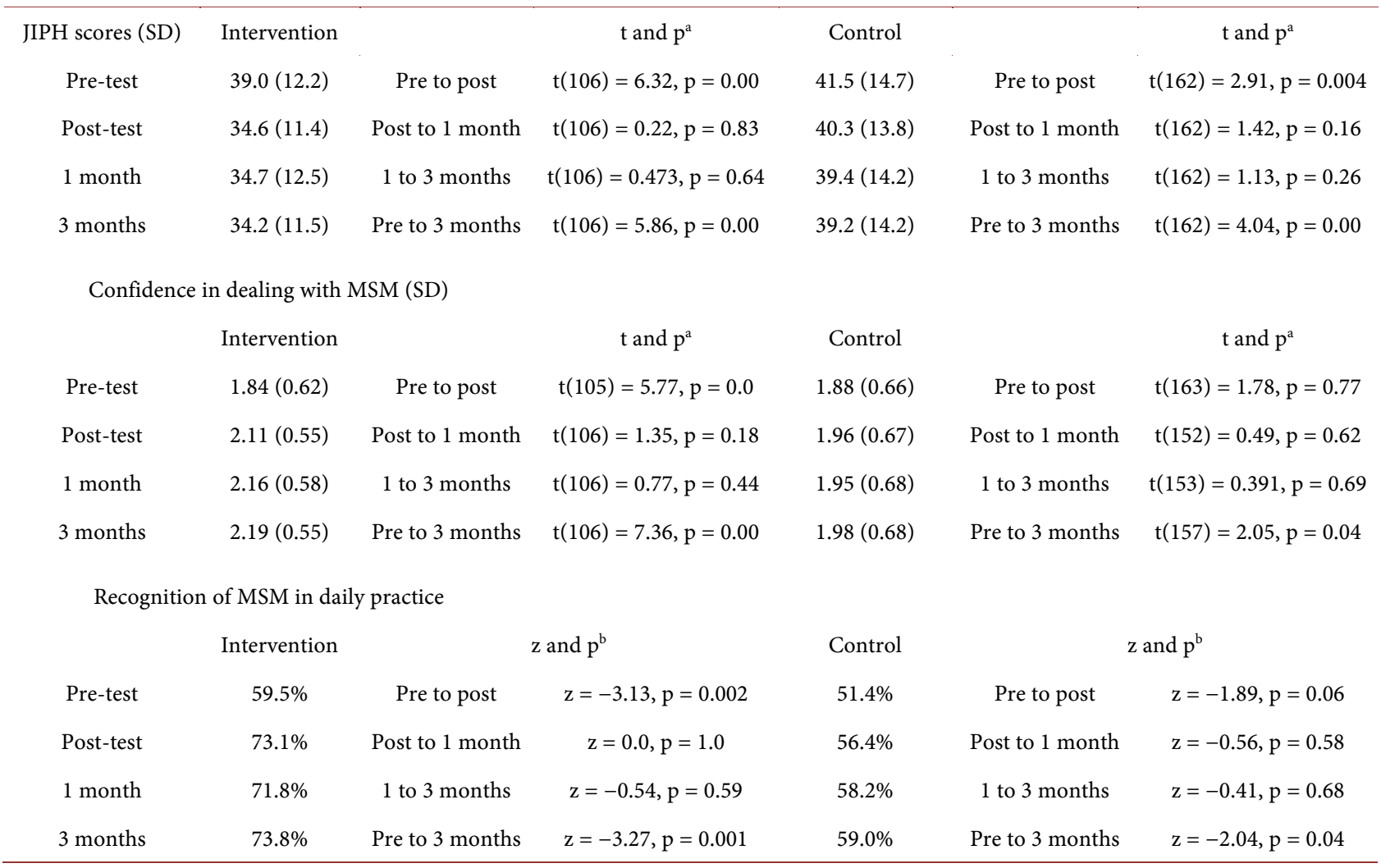

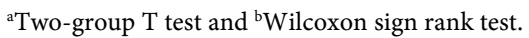


$(t(106)=7.36, p=0.00)$. The other comparisons were not significant. These results imply that confidence increased after training and remained high at 3 months after the training. In the control group, there was a significant differences in mean scores between pre-test and 3 months $(t(157)=2.05, \mathrm{p}=0.04)$. The other comparisons were not significant.

Regarding the recognition of MSM in daily life, in the intervention group, there was a significant difference in scores between pre-test and post-test $(\mathrm{z}=$ $-3.13, \mathrm{p}=0.002)$ and between pre-test and follow-up at 3 months $(\mathrm{z}=-3.27, \mathrm{p}=$ $0.001)$; none of the other differences were significant. Thus, the significant increase in recognition of MSM was maintained between post-test and the followup at 3 months. In the control group, there were no significant differences in scores except for an increase between pre-test and the follow-up at 3 months ( $\mathrm{z}$ $=-2.04, \mathrm{p}=0.04)$.

\section{Discussion}

The study aim was to examine the effect of a training session on recognition and understanding of MSM in daily life among Japanese public health nurses, to improve their ability to care for MSM.

\subsection{JIPH Scores}

There were no significant differences in JIPH scores between the intervention and control groups at pre-test. However, in the intervention group, there were significant decreases in JIPH scores between pre-test and post-test and between pre-test and the follow-up at 3 months. The same changes were observed in the control group. The JIPH mean scores were 39.0 and 41.5 at pre-test in the intervention and control groups, indicating that the sample was moderately nonhomophobic. Compared to Japanese graduate students in psychology, the present sample was less homophobic (55.97 for male, 51.44 for females) [20], while compared to American social workers, the sample of this study was almost the same (39.7 for males and 37.6 for females) [21].

The result showed that the JIPH score significantly decreased from pre-test to post-test, and that these changes were maintained until 3 months after the training session in both groups. The results for the intervention group might indicate an intervention effect on homophobic attitudes. Importantly, the JIPH scores for the intervention group decreased more than did the control group scores. In contrast, the decrease for the control group may have been learning effects - namely, responding four to the same questionnaire-and perhaps reports by colleagues who participated in the training. Adding to the interpretation is that the intervention group also answered an open-answer question about their changes in attitudes toward MSM after the intervention. One participant noted that, "After the training, my attitudes toward MSM drastically changed, from [being] 'strange people' to the 'same as us'".

There have been few studies of interventions aiming to reduce homophobic attitudes [22]. In one previous interventional study for nurses in the United 
States, a 1-hour infomercial had no effect on homophobic attitudes [14]. Another study on college students used a 45-minute video about homosexuality and lectures and discussion with homosexual people in the classroom, and then compared its effect with that of control students. However, no decrease in homophobic attitudes in either group was observed [13]. There was, however, a significant decrease in Index of Homophobia (IHP) scores after graduate and undergraduate students took a human sexuality course in university in another study [12]. The results of this study suggest a significant decrease and maintenance of this decrease in JIPH scores, even though the intervention was very short. Nevertheless, a relatively long-term decrease in homophobic attitudes was still observed, even though the lectures were given by psychologists rather than MSM themselves.

Often, interventional studies on health care providers who deal with HIV use stigma about HIV-positive patients as the outcome. As noted above, only a few HIV interventional studies have used homophobia as the outcome. One previous study compared the effects of an educational program providing knowledge of AIDS and a program that combined this AIDS-knowledge education with contact with people with HIV/AIDS among nursing students in China. The results showed that the group who underwent the combined program exhibited a significant decrease in stigmatizing attitudes at post-test; however, this decrease did not last until the follow-up at 6weeks [23]. Taken together, despite the possible influence of learning effects for the questionnaires, the current results could demonstrate that the training led to decreased homophobic attitudes in the long-term.

\subsection{Confidence in Dealing with MSM}

There were no significant differences between the two groups at pre-test. In the intervention group, there were significant increases in scores between pre-test and post-test, and this increase was maintained by the 3-month follow-up. This implies that confidence increased after training. In the control group, there was a significant increase between pre-test and the follow-up at 3 months. The reasons for this increase could be similar to those for the JIPH—namely, learning effects and colleague reports.

As mentioned previously, there is very little research on confidence in dealing with MSM, which is a novel aspect of this study. The training session did not feature a lecture by an MSM speaker; instead, the importance of getting to know more about MSM was stressed, and statistics on MSM's daily lives and health issues were provided. Furthermore, comics and other resources to help others inform the reality of MSM were introduced and a local resource list was distributed during the training. These more active, stimulating learning methods might have built their confidence to a greater degree than merely attending a lecture by an MSM speaker as passive participants.

Several intervention group participants wrote in the open-answer section on attitudes toward MSM, "Before the training, I was obsessed with whether the 
client is an MSM or not", "Before I was reluctant to ask about a client's sexual orientation, but now I don't feel that", and “At the negative result notification, I am trying to look back with the client on their risky behavior, and give information about prevention, after that, I am trying to think how I can reduce risk with the clients". These comments suggest that they used what they had learned from the training session. Furthermore, the training advised the nurses to use rather easily implemented strategies, such as the distribution of pamphlets for MSM and avoiding supposing that the client is heterosexual (which may effectively prevent MSM from talking about their sexual behavior) [6]. The importance of creating an atmosphere to help the client talk about their sexual orientation was also stressed in this training. Several open-answer responses revealed that participants did indeed follow these suggestions: "[I] browse the blogs of HIV positive MSM", "I distribute pamphlets for MSM", and "[I] planned training about MSM with PHNs who obtained knowledge at the training and sought the support of nonprofit organizations". Employing these strategies might have contributed to increasing and maintaining their confidence after the training.

\subsection{Recognition of MSM in Daily Life}

Again, there were no significant differences inrecognition of MSM between the two groups at pre-test. However, in the intervention group, there was a significant increase in scores by the post-test and a maintenance of these scores by the 3-month follow-up. The control group demonstrated no change at post-test, but there was a significant increase by the 3-month mark (suggesting learning and colleague effects). The open-answer responses suggested that the training contributed to the increased scores in the former group: "there are many clients with various sexual orientations in HIV counseling and testing, and I understood the importance of creating a comfortable counseling environment for talking about sexual behavior at ease." In other words, the participant seemed to have learned how to easily acknowledge that people undergoing HIV testing have various sexualities.

During HIV counseling and testing, counselors should provide clients with support to minimize the client's further risky behavior, in line with that client's behavior and situation, in order to ensure a reduction in HIV risk [4]. However, if public health nurses do not recognize that their clients are MSM, their counseling would not be as effective because they it would not be tailored specifically for that client's individual situation. Unfortunately, there appear to be no studies on the recognition of MSM in daily life. This suggests that the findings of this study are novel.

\subsection{Limitations}

Overall, the results indicate that the three-hour training was effective for improving the attitudes toward MSM and building the confidence. Intervention group participants were significantly younger than were the control group, and had significantly fewer years of experience. At pre-test, there were no significant 
differences among the outcomes, which suggests the difference in age and experience had no effect on the outcomes Nevertheless, this study had some limitations. First, there are limited interventional studies on this topic in Asian countries. Thus, although the findings are likely valuable for improving preventive efforts in Japan, they may be inappropriate for application to other countries because of the difference in epidemiological structures and the nursing profession. Second, random sampling of the participants was not performed in this study. Third, as many public health nurses in the intervention group are involved in treating HIV/AIDS, their daily work after training might have had a learning effect, and thus influenced the results. To deepen current understanding of the findings of this research and manage selection bias in subsequent studies, participants could be stratified. Finally, the precise effects of specific contents of the training on the outcomes were not determined; thus, a deeper analysis of the data is needed to grasp the factors related to the confidence or homophobic attitudes. This would be useful for improving training.

\subsection{Implications for Public Health Nursing and Education}

As pointed out above, in Japan, the proportion of the total population who are LGBT is $7.6 \%$ [24]. It is necessary for nursing professionals to recognize the diversity of sexuality in order to provide better care to this population. It is strongly recommend that the nursing curriculum cover the diversity of sexuality and give nursing students the opportunity to reflect on their attitudes toward sexuality, which can foster a greater awareness and sensitivity to the diversity of potential clients. In Japan, because public health nurse often provide HIV test counseling, it is strongly recommended that they be provided within-service education such as short training session to improve their capacity to deal with MSM. However, relatively little is known about the homophobic attitudes of public health nurses in Japan, and what specific educational components will effectively reduce stigma and homophobic attitudes. As such, further research will be needed.

\section{Conclusion}

The objective of this study was to determine the effect of a three-hour training session on recognition and understanding of MSM in daily life among Japanese public health nurses to provide better care for them. The analysis of the results suggests that there was a significant decrease in homophobic attitudes and a significant increase in confidence in dealing with MSM and realization of MSM in daily settings. These changes were maintained until 3 months.

\section{Acknowledgements}

This work was supported by Health Labor Sciences Research Grant, Research on HIV/AIDS (grant number 201319005B) from the Ministry of Health, Labour and Welfare. 


\section{Conflict of Interest}

The authors declare that no conflict of interest exists concerning this study.

\section{References}

[1] AIDS Surveillance Committee, Ministry of Health, Labour and Welfare (2016) The Annual Report on AIDS Trends in 2015.

http://api-net.jfap.or.jp/status/2015/15nenpo/15nenpo menu.html

[2] Ministry of Health, Labour and Welfare (2012) The National AIDS Prevention Guideline in 2012.

http://www.mhlw.go.jp/seisakunitsuite/bunya/kenkou iryou/kenkou/kekkaku-kans enshou/aids/dl/yoboushishin.pdf

[3] Hidaka, Y., Kimura, H. and Homma, T. (2009) Internet-Based Behavioral Epidemiological Survey on HIV Prevention Behavior among Men who Sex with Men. REACH Online 2008-Annual Report of Health Labour Sciences Research Grant, Research on HIV/AIDS, Research on HIV Preventive Intervention for Internet Users and monitoring Report 2009, Kyoto.

[4] Japan Foundation for AIDS Prevention (2011) Guideline on HIV Test and Counseling Training (Basic). http://www.hivkensa.com/kenshu/

[5] Mizuno, M. and Fukuda, H. (2009) Education on Sexuality in the Basic Nursing Education Course-Analysis of syllabi-. Japanese Journal of Maternal Health, 49, 612-619.

[6] Hidaka, Y. (2007) Gay, Bisexual Men's Health Report 2. http://www.j-msm.com/report/report02/report02 all.pdf

[7] UNFPA, The Global Forum on MSM and HIV, UNDP, UNAIDS, WHO, United States Agency for International Development, the US President's Emergency Plan for AIDS Relief, and the Bill \& Melinda Gates Foundation (2015) Implementing Comprehensive HIV and STI Programmes with Men Who Have Sex with Men: Practical Guidance for Collaborative Interventions.

http://www.unfpa.org/sites/default/files/pub-pdf/MSMIT\%20\%282015\%20Final\%2 0for\%20web\%29.pdf

[8] Schlub, S.M. and Martsolf, D.S. (1999) Orthodox Christian Beliefs and Homophobia in Baccalaureate Nursing Students. Nursing Forum, 34, 15-22.

https://doi.org/10.1111/j.1744-6198.1999.tb00982.x

[9] Jin, H., Earnshaw, V.A., Wickersham, J.A., Kamarulzaman, A., Desai, M.M., John, J. and Altice, F.L. (2014) An Assessment of Health-Care Students' Attitudes toward Patients with or at High Risk for HIV: Implications for Education and Cultural Competency. AIDS Care, 26, 1223-1228.

https://doi.org/10.1080/09540121.2014.894616

[10] Yen, C.-F., Pan, S.-M., Hou, S.-Y., Liu, H.-C., Wu, S.-J., Yang, W.-C. and Yang, H.H. (2007) Attitudes toward Gay Men and Lesbians and Related Factors among Nurses in Southern Taiwan. Public Health, 121, 73-79. https://doi.org/10.1016/j.puhe.2006.08.013

[11] Röndahl, G., Innala, S. and Carlsson, M. (2004) Nurses' Attitudes towards Lesbians and Gay Men. Journal of Advanced Nursing, 47, 386-392.

https://doi.org/10.1111/j.1365-2648.2004.03116.x

[12] Chonody, J.M., Siebert, D.C. and Rutledge, S.E. (2009) College Students' Attitudes toward Gays and Lesbians. Journal of Social Work Education, 45, 499-512. https://doi.org/10.5175/JSWE.2009.200800002

[13] Cotten-Huston, A.L. and Waite, B.M. (2000) Anti-Homosexual Attitudes in College 
Students: Predictors and Classroom Interventions. Journal of Homosexuality, 38, 117. https://doi.org/10.1300/J082v38n03 07

[14] Zachariah, G.S. (1998) AIDS Fear in Health Care Workers: Development of Educational Program to Decrease the Fear. PhD Dissertation, Spalding University, Louisville.

[15] Nishimura, Y.H., Iwai, M., Ozaki, A., Waki, A. and Hidaka, Y. (2016) State of HIV Testing and Consultation Services at Health Centers in the Kinki Region of Western Japan. The Japanese Society for AIDS Research, 18, 20-28.

[16] Inaba, M. (1994) How Has Japanese Psychiatry Dealt with Homosexuality? Syakai Rinsyou Zasshi, 2, 34-43.

[17] Morrissey, M. and Rivers, I. (1998)Applying the Mims-Swenson Sexual Health Model to Nurse Education Offering an Alternative Focus on Sexuality and Health Care. Nurse Education Today, 18, 488-495. https://doi.org/10.1016/S0260-6917(98)80175-5

[18] Kaji, Y. (1995) Developing an Instrument to Measure Attitudes toward Homosexuality among Contemporary Japanese. Dissertation, School of Education, New York University, New York.

[19] Hudson, W.W. and Ricketts, W.A. (1980) A Strategy for the Measurement of Homophobia. Journal of Homosexuality, 5, 357-372. https://doi.org/10.1300/J082v05n04 02

[20] Shinagawa, Y. (2006) Counselor's Gender and Clinical Bias against Gay Men. Bulletin of the Graduate School of Education, Hiroshima University. Part 3, Education and Human Science, 55, 297-306.

[21] Berkman, C.S. and Zinberg, G. (1997) Homophobia and Heterosexism in Social Workers. Social Work, 42, 319-332. https://doi.org/10.1093/sw/42.4.319

[22] Sengupta, S., Banks, B., Jonas, D., Miles, M.S. and Smith, G.C. (2011) HIV Interventions to Reduce HIV/AIDS Stigma: A Systematic Review. AIDS and Behavior, 15, 1075-1087. https://doi.org/10.1007/s10461-010-9847-0

[23] Yiu, J.W., Mak, W.W., Ho, W.S. and Chui, Y.Y. (2010) Effectiveness of a Knowledge-Contact Program in Improving Nursing Students' Attitudes and Emotional Competence in Serving People Living with HIV/AIDS. Social Science \& Medicine, 71, 38-44. https://doi.org/10.1016/j.socscimed.2010.02.045

[24] Dentsu (2015) LGBT Survey. http://www.dentsu.co.jp/news/release/2015/0423-004032.html 
Submit or recommend next manuscript to SCIRP and we will provide best service for you:

Accepting pre-submission inquiries through Email, Facebook, LinkedIn, Twitter, etc. A wide selection of journals (inclusive of 9 subjects, more than 200 journals)

Providing 24-hour high-quality service

User-friendly online submission system

Fair and swift peer-review system

Efficient typesetting and proofreading procedure

Display of the result of downloads and visits, as well as the number of cited articles Maximum dissemination of your research work

Submit your manuscript at: http://papersubmission.scirp.org/

Or contact ojn@scirp.org 